\title{
Psychosomatic and vasomotor symptom changes during transition to menopause
}

\author{
Areti Augoulea ${ }^{1,2}$, Michalis Moros ${ }^{1,2}$, Aikaterini Lykeridou ${ }^{3}$, George Kaparos ${ }^{1,4}$, Rallou Lyberi ${ }^{1,2}$, \\ Konstantinos Panoulis ${ }^{1,2}$
}

${ }^{1} 2^{\text {nd }}$ Department of Obstetrics and Gynaecology, University of Athens Medical School, Athens, Greece

2Department of Climacterium and Menopause, Aretaieion Hospital, Athens, Greece

${ }^{3}$ Department of Midwifery, University of West Attica, Athens, Greece

${ }^{4}$ Department of Biopathology, Aretaieion Hospital, Athens, Greece

\begin{abstract}
Menopause is the condition in which the gradual decline in ovarian function finally leads to the permanent cessation of menstruation. Oestrogen deficiency may cause early symptoms during the menopausal transition and late symptoms after menopause. Menopause is a normal period of life. During this period, women need adaptation to new biological, social, and psychological parameters. Vasomotor symptoms are among the most common menopausal symptoms. Menopause per se is not correlated with specific psychiatric disorders, but data suggest that perimenopausal women are more likely to develop depressive disorders even without a previous history. Vasomotor symptoms are correlated with mood and sleep disturbances, neuroticism, anxiety, decreased cognitive function, and stress. Personality traits, social, and other factors are also important mediators of vasomotor symptoms during the menopausal transition phase.

This is a review based on the existing evidence concerning the correlation between psychosomatic and vasomotor symptoms of menopause during the menopausal transition period. Healthcare providers should take these correlations into consideration when planning the treatment of vasomotor symptoms. Vasomotor symptoms during menopause are associated with significant social costs. There are numerous traditional hormone therapy, and complementary and alternative therapy including over-the-counter treatments and dietary supplements for managing menopause-related vasomotor symptoms. Additional costs include follow-up physician visits, laboratory testing, management of adverse events, and loss of productivity at work. Social support and planning may help women to deal with menopausal symptoms and may reduce overall social costs during this transitional phase.
\end{abstract}

Key words: vasomotor symptoms, personality traits, menopause.

\section{Introduction}

Menopause is the condition in which the gradual decline in ovarian function, having started usually during the fourth decade of life, finally leads to the permanent cessation of menstruation. The permanent loss of the reproductive function in women is established at a median age of 51.25 years in Poland [1]. Genetic factors may affect the age at which menopause is established [2]. Menopause may occur earlier in nulliparous, in smokers, or due to oophorectomy, chemotherapy, and radiation to the pelvic area [3]. Oestrogen deficiency may cause early symptoms during the menopausal transition and late symptoms after menopause due to the abundance of oestrogen receptors (ORs) in most organs and systems. Menopausal transition is characterised by a variety of menstruation disturbances. During this period of life, the appearance of vasomotor symptoms like hot flushes and night sweats are common, sometimes with psychosomatic symptoms like mood disturbances and decrease in libido. Urogenital symptoms like dyspareunia are common during perimenopause and usually worsen as women become older affecting negatively women's sexual life [4].

Adverse health outcomes and diseases like cardiovascular disease (CVD) and osteoporosis may affect women later after the establishment of menopause. CVD is the main cause of death globally in both sexes. Ischaemic strokes seem to cause more severe disabilities to women after menopause than in men [5]. The risk for vascular cerebral disease is almost dou- 
bled within the first decade since menopause [6]. Post-menopausal osteoporosis is estimated to affect 22 million women in Europe and has led to 3.5 million osteoporotic fractures. Fractures are correlated with increased morbidity and mortality [7]. Osteoporosis is increasing steadily because of the aging of the world population and currently affects more than 10 million people in the United States [8]. Osteoporosis will arrive to impact approximately 14 million adults over the age of 50 by the year 2020. Hormone therapy together with specific interventions, such as physical exercise [9], cessation of smoking [10], and reduction in alcohol intake, may prevent osteoporosis and risk for fractures.

In this narrative review article, we conducted a literature search in PubMed, targeting to the most recent publications that associate psychosomatic and vasomotor symptoms of menopause during the menopausal transition and the management of these through hormone e non hormone therapy. The search terms that were used were "vasomotor symptoms", "personality traits", "menopause" in combination with the terms "hormone therapy", "non-hormone therapy", and "psychosomatic symptoms". Fifty-seven articles were read in full to determine eligibility and classification. Non-English experimental and review studies, as well as case reports and studies in pregnant women, children, and adolescents were excluded. After applying exclusion criteria, 40 studies were discussed in this review: 26 original articles and 14 reviews, systematic reviews, meta-analysis, and position statements (Fig. 1, Tables 1-3) [11].

The purpose of this narrative review of the literature is the association between psychosomatic and vasomotor symptoms of menopause during the menopausal transition and the management of these through hormone and non-hormone therapy. Vasomotor symptoms during menopause are associated with significant social costs. Social support and planning may help women to deal with menopausal symptoms and may reduce overall social costs during this transitional phase.

\section{Early perimenopausal symptoms}

Menopause is a normal period of life. Most of women experience menopause between the ages of 45 and 55 years and approximately $5 \%$ earlier, between the ages of 40 and 45 years [12]. Most cohorts include postmenopausal women in the age range 50 to 79 years [13]. During this period, women need adaptation to new biological, social, and psychological parameters. At the same time, women have to deal with hormonal and somatic changes and with non-familiar conditions like unfortunate family events, the transition to a new family, different social roles, the loss of fertility, pension, etc. [14, 15].

Vasomotor symptoms are among the most common menopausal symptoms. $50.3 \%$ to $82.1 \%$ of meno- pausal women experience vasomotor symptoms, and their frequency, duration, and intensity vary [14]. Their aetiology is not well understood, but it is believed that they are caused by a decrease in the range of the thermo neutral zone of the hypothalamus [16]. Hormonal and non-hormonal therapeutic interventions are now available for the relief from vasomotor symptoms [17]. Hot flushes and sweats during the night result in sleep disturbances. The SWAN study has shown that $38 \%$ of women aged between 40 and 55 years reported sleep deficiency [18]. Similar studies in the USA have shown that the most frequently reported problems were maintaining sleep (25.9\%) and early awakening (12.4\%) [19]. Various other factors such as smoking, exercise, anxiety, depression, and oestradiol levels positively or negatively affect sleep in menopausal women [20].

Genitourinary syndrome of menopause (GSM) commonly disturbs women's sexual life due to infections, dyspareunia, and atrophy. Decrease in libido and sexual function is not always a condition of GSM. General health condition, the presence of a healthy and sexually available partner [21], psychological factors, and urogenital atrophy are very important parameters [22].

\section{Mood-sleep disturbances and vasomotor symptoms}

Depression or "depressive disorders" is a term used to describe a state of lower mood as a result of various conditions. The Diagnostic and Statistical Manual

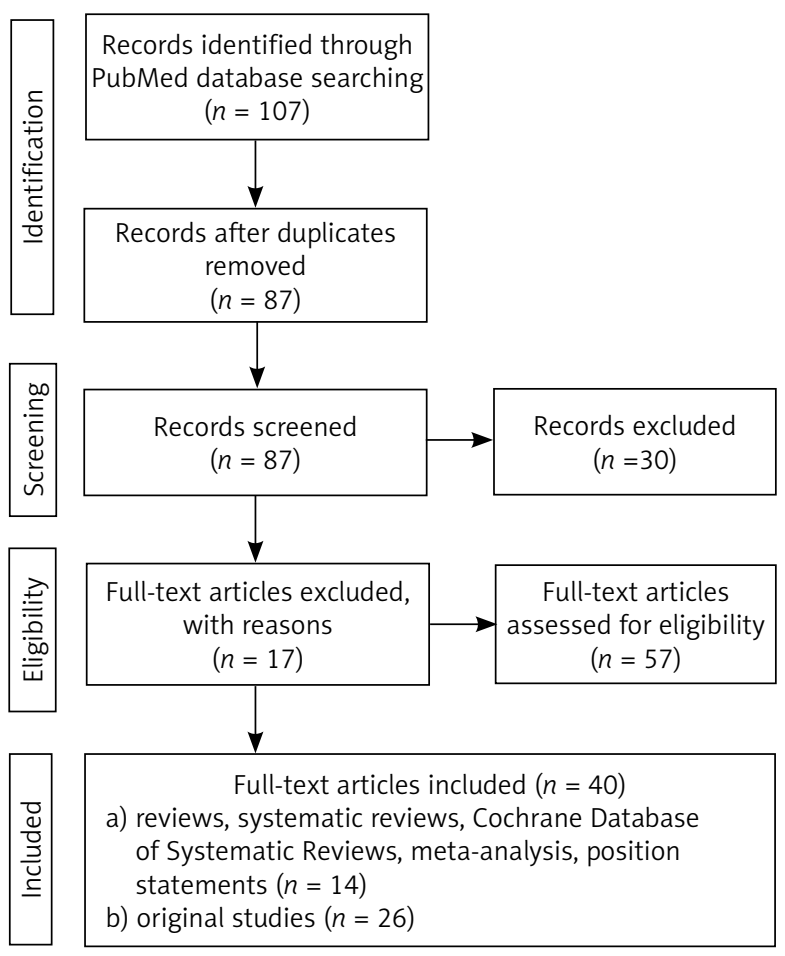

Fig. 1. Narrative review study flow diagram 
Table 1. Review results on early perimenopausal symptoms

\begin{tabular}{llll}
\hline Ref. & \multicolumn{1}{c}{ Design } & \multicolumn{1}{c}{ Early symptom } & Results \\
\hline$[42]$ & Community survey & Sleep difficulty & Menopausal transition is associated with sleep difficulty \\
\hline$[19]$ & $\begin{array}{l}\text { Cross-sectional } \\
\text { (SWAN sleep study) }\end{array}$ & Mood-sleep symptoms & $\begin{array}{l}\text { Contrary to expectations, association with longer sleep } \\
\text { duration }\end{array}$ \\
\hline$[43]$ & Cross-sectional study & Sleep difficulty & $\begin{array}{l}\text { Measures of sleep are associated with metabolic } \\
\text { syndrome in midlife women }\end{array}$ \\
\hline$[44]$ & Cross-sectional study & Sexual function symptoms & Association with the quality of sexual life \\
\hline$[45]$ & Online survey on prevalence & $\begin{array}{l}\text { Vasomotor } \\
\text { and vaginal symptoms }\end{array}$ & High rate of these symptoms in postmenopausal women \\
\hline$[46]$ & Systematic review & $\begin{array}{l}\text { Vasomotor symptoms, anxiety, } \\
\text { depression }\end{array}$ & $\begin{array}{l}\text { Association of menopausal symptoms with increased } \\
\text { risk of CVD }\end{array}$ \\
\hline
\end{tabular}

Table 2. Review results on mood-sleep disturbances and vasomotor symptoms

\begin{tabular}{|c|c|c|c|}
\hline Ref. & Design & Mood-sleep symptoms & Results \\
\hline$[46]$ & $\begin{array}{l}\text { Longitudinal epidemiological } \\
\text { prospective study }\end{array}$ & $\begin{array}{l}\text { Negative mood, } \\
\text { depressive symptoms }\end{array}$ & $\begin{array}{l}\text { Association between these symptoms and menopausal } \\
\text { transition }\end{array}$ \\
\hline$[46]$ & $\begin{array}{l}\text { Longitudinal observational } \\
\text { study from SWAN study }\end{array}$ & Depressive symptoms & $\begin{array}{l}\text { High depressive symptoms during perimenopause } \\
\text { and post-menopause }\end{array}$ \\
\hline$[46]$ & Systematic review & Mood disorders & $\begin{array}{l}\text { Vasomotor symptoms, anxiety, are correlated to the } \\
\text { risk of menopause related depression }\end{array}$ \\
\hline [46] & Systematic review & $\begin{array}{l}\text { Vasomotor symptoms } \\
\text { and depression }\end{array}$ & $\begin{array}{l}\text { Bias makes the conclusion of any association between } \\
\text { these symptoms difficult }\end{array}$ \\
\hline [46] & Systematic review & $\begin{array}{l}\text { Vasomotor symptoms } \\
\text { and depression }\end{array}$ & $\begin{array}{l}\text { There was a bidirectional association between these } \\
\text { symptoms during menopausal transition }\end{array}$ \\
\hline$[46]$ & Meta-analysis of 11 studies & Depressive symptoms & $\begin{array}{l}\text { Perimenopause is a vulnerable period of developing } \\
\text { depressive symptoms }\end{array}$ \\
\hline$[46]$ & Cross-sectional & Depressive symptoms & $\begin{array}{l}\text { Severe vasomotor symptoms worsened depressive } \\
\text { symptoms }\end{array}$ \\
\hline [30] & Review & Depression & $\begin{array}{l}\text { There is an association between depressive symptoms } \\
\text { and menopausal transition }\end{array}$ \\
\hline [46] & Cross-sectional & $\begin{array}{l}\text { Vasomotor symptoms } \\
\text { and depression }\end{array}$ & $\begin{array}{l}\text { These symptoms are associated with different patterns } \\
\text { of sleep disturbances }\end{array}$ \\
\hline$[46]$ & Longitudinal study & Sleep disturbances & This is a significant issue for midlife women \\
\hline$[46]$ & $\mathrm{RCT}$ & Vasomotor symptoms & $\begin{array}{l}\text { Frequency-severity have a linear relationship } \\
\text { with menopause specific quality of life and sleep }\end{array}$ \\
\hline$[46]$ & Cross-sectional & Sleep difficulty & $\begin{array}{l}\text { Vasomotor symptoms may influence sleep in breast } \\
\text { cancer survivors }\end{array}$ \\
\hline [35] & $\begin{array}{l}\text { Community-based study } \\
\text { (SWAN sleep study) }\end{array}$ & Sleep difficulty and pain & $\begin{array}{l}\text { Higher night-time pain levels are associated with less } \\
\text { efficient sleep }\end{array}$ \\
\hline
\end{tabular}

Table 3. Review results on personality traits and vasomotor symptoms

\begin{tabular}{|c|c|c|c|}
\hline Ref. & Design & Personality traits & Results \\
\hline$[46]$ & Correlation study & Personality characteristics & $\begin{array}{l}\text { There was a correlation between intensity of hot flashes and night } \\
\text { sweats and conscientiousness }\end{array}$ \\
\hline [46] & Review & $\begin{array}{l}\text { Neuroticism } \\
\text { and mental disorders }\end{array}$ & Neuroticism is an efficient marker of non-specified general risk \\
\hline [46] & Cross-sectional & Women's personality & Personality would play an important role in women's quality of life \\
\hline$[46]$ & Community study & $\begin{array}{l}\text { Extroversion } \\
\text { and neuroticism }\end{array}$ & $\begin{array}{l}\text { Lower levels of extroversion are associated with higher levels } \\
\text { of depression and neuroticism }\end{array}$ \\
\hline$[46]$ & Community study & Previous depression & $\begin{array}{l}\text { Previous depression could not predict depressive symptoms } \\
\text { over } 30 \text { months }\end{array}$ \\
\hline$[46]$ & $\begin{array}{l}\text { Internet survey in } \\
5 \text { countries }\end{array}$ & Behaviours and attitudes & $\begin{array}{l}\text { Education concerning women's attitudes toward treatment should be } \\
\text { provided to those physicians who treat menopause in each country }\end{array}$ \\
\hline
\end{tabular}


(DSM) is used by the psychologists for various conditions having mood disorders like major depressive disorder, dysthymia, and bipolar disorder. Women are at a two-times greater risk for developing depression as compared to men. Recent longitudinal studies have documented an increased risk of depressive symptoms during the menopausal transition [23].

Menopause per se is not correlated with specific psychiatric disorders, but data suggest that perimenopausal women are more likely to develop depressive disorders even without a previous history [24]. Additionally, women with positive history are much more likely to relapse, and data also suggest that there is a correlation between vasomotor symptoms and depressive disorders [25]. A systematic review of 33 relevant studies has shown that there is a positive association between vasomotor symptoms and depressive symptoms during perimenopause [26]. Similar findings have been demonstrated by other studies [27], in which there seems to be a greater impact of vasomotor symptoms on depressive symptoms during the menopausal transition phase rather than during the post-menopausal or the pre-menopausal phase. This has also been reported by a recent meta-analysis [28]. Severe vasomotor symptoms worsened depressive symptoms in a cross-sectional survey of 1358 women aged 45-70 years old in Boston [29]. Other risk factors include unfortunate life events, a negative mood towards menopause, lifestyle, the quality of the relationship between the partners, and surgical menopause [30].

There seems to be a positive correlation between depressive disorders and sleep disorders [31]. Vasomotor symptoms have been among the most influencing factors of sleep disturbances [32] and are also directly associated with menopause-specific quality of life [33]. Moreover, vasomotor symptoms, through the negative effect on sleep, can also influence women's mood [34] and the sense of restlessness during the day [35]. Vasomotor symptoms may cause sleep disturbances [31] and frequent awakenings during the night. The overall sleep duration and quality is diminished and leads to fatigue during the following day. Mood seems to be negatively affected by this situation [19].

\section{Personality traits and vasomotor symptoms}

Frequency and intensity of vasomotor symptoms may not only be restricted to endocrine and other physiological factors but may also be attributed, to a degree, to specific personality traits as well as to social, cultural, and demographic parameters. It has also been suggested that in women who live in societies in which aging and menopause are not considered as negative life events but rather as natural consequences of the life, vasomotor symptoms are less frequently reported.
Data from some studies have shown that high levels of neuroticism and anxiety may lead to increased perceived severity of vasomotor symptoms whereas high conscientiousness and extroversion scores have been positively correlated with decreased severity of hot flushes and nights sweats [36]. These findings may be attributed to the fact that people with high levels of neuroticism experience more anxiety and depressed mood and are less able to effectively cope with stress. At the same time, they are more likely to develop neuroses [37]. On the other hand, people with high conscientiousness and extraversion scores are more open to new experiences, considering them to be more challenging than threatening events, and at the same time they are more willing to discuss them and thus to acquire more social support when dealing with menopausal symptoms. Furthermore, neuroticism has been shown to be a predictor of depressive symptoms in middle-aged women. Women in midlife with high levels of neuroticism experience more psychological symptoms, including depression or anxiety, irritability, tearfulness, and feelings of panic, and thus their quality of life is negatively affected [38]. Lin et al. found menopausal status as a predictor of depressive symptoms among climacteric women during the menopause transition and found this to be mediated by neuroticism [39]. Recently research suggested that neuroticism played an important role in the persistence of depression among climacteric women after 30 months follow-up [40].

\section{Management options for menopausal symptoms}

Non-vasomotor symptoms, including depression, insomnia, panic attacks, and their association with vasomotor symptoms can vary greatly between women. Hormone therapy therefore has been considered as the most effective treatment for these symptoms [14]. In women who experience natural menopause at the normal age range the basic reason to start hormone therapy (oestrogen with progestogen in women with a uterus, or oestrogen alone in women without a uterus) is moderate and severe vasomotor symptoms. Menopausal women may benefit from hormone therapy not only to manage symptoms, but also to maintain bone density and reduce the cardiovascular psychological and neuro-cognitive effects of oestrogen deficiency. If no contraindications exist, hormone therapy is recommended at least until the natural age of menopause. The aim of hormone therapy is the protection against the negative effects, and it may be considered for a longer duration if needed based on symptoms duration and severity [15]. Traditional hormone therapy, and complementary and alternative therapy including over-the-counter treatments, dietary supplements, and 
exercise for managing menopause-related vasomotor symptoms are substantial.

\section{Conclusions}

Vasomotor symptoms are correlated with mood and sleep disturbances, neuroticism, cognitive function, anxiety, and stress. All these symptoms can have a significant negative effect on the quality of life for a large number of women. The physiology underlying vasomotor symptoms is complex and not fully understood. Personality traits, and social and other factors are also important mediators of vasomotor symptoms during the menopausal transition phase. Vasomotor symptoms during menopause are associated with significant social costs. There are numerous traditional hormone therapy, and complementary and alternative therapy including over-the-counter treatments and dietary supplements, for managing menopause-related vasomotor symptoms. Additional costs include follow-up physician visits, laboratory testing, management of adverse events, and loss of productivity at work. Among women with vasomotor symptoms the greatest proportion do not seek treatment or counselling and medical aid [41]. Social support and planning may help women to deal with menopausal symptoms and may reduce overall social costs during this transitional phase. Healthcare providers should take these correlations into consideration when planning the treatment of vasomotor symptoms.

\section{Disclosure}

The authors report no conflict of interest.

\section{References}

1. Kaczmarek M. The timing of natural menopause in Poland and associated factors. Maturitas 2007; 57: 139-153.

2. Laven JS. Genetics of Early and Normal Menopause. Semin Reprod Med 2015; 33: 377-383.

3. Edwards H, Duchesne A, Au AS, Einstein G. The many menopauses: searching the cognitive research literature for menopause types. Menopause 2019; 26: 45-65.

4. Portman DJ, Gass ML, Vulvovaginal Atrophy Terminology Consensus Conference Panel, et al. Genitourinary syndrome of menopause: new terminology for vulvovaginal atrophy from the International Society for the Study of Women's Sexual Health and the North American Menopause Society. Menopause 2014; 21: 1063-1068.

5. Lisabeth LD, Beiser AS, Brown DL, et al. Age at natural menopause and risk of ischemic stroke: the Framingham heart study. Stroke 2009; 40: 1044-1049.

6. Lisabeth L, Bushnell C. Stroke risk in women: the role of menopause and hormone therapy. Lancet Neurol 2012; 11: 82-91.

7. Hernlund E, Svedbom A, Ivergård M, et al. Osteoporosis in the European Union: medical management, epidemiology and economic burden. A report prepared in collaboration with the International Osteoporosis Foundation (IOF) and the European Federation of Pharmaceutical Industry Associations (EFPIA). Arch Osteoporos 2013; 8: 136.

8. Lewiecki EM, Leader D, Weiss R, Williams SA. Challenges in osteoporosis awareness and management: results from a survey of US postmenopausal women. J Drug Assess 2019; 8: 25-31.
9. Gillespie LD, Robertson MC, Gillespie WJ, et al. Interventions for preventing falls in older people living in the community. Cochrane Database Syst Rev 2012: CD007146.

10. Ayo-Yusuf OA, Olutola BG. Epidemiological association between osteoporosis and combined smoking and use of snuff among South African women. Niger J Clin Pract 2014; 17: 174-177.

11. Moher D, Liberati A, Tetzlaff J, et al. Preferred reporting items for systematic reviews and meta-analyses: the PRISMA statement. PLoS Med 2009; 6: e1000097.

12. Miro F, Parker SW, Aspinall LJ, et al. Sequential classification of endocrine stages during reproductive aging in women: the FREEDOM study. Menopause 2005; 12: 281-290.

13. Shadyab AH, Macera CA, Shaffer RA, et al. Ages at menarche and menopause and reproductive lifespan as predictors of exceptional longevity in women: the Women's Health Initiative. Menopause 2017; 24: 35-44.

14. Muka T, Oliver-Williams C, Colpani V, et al. Association of Vasomotor and Other Menopausal Symptoms with Risk of Cardiovascular Disease: A Systematic Review and Meta-Analysis. PLoS One 2016; 11: e0157417.

15. Faubion SS, Kuhle CL, Shuster LT, Rocca WA. Long-term health consequences of premature or early menopause and considerations for management. Climacteric 2015; 18: 483-491.

16. Archer DF, Sturdee DW, Baber R, et al. Menopausal hot flushes and night sweats: where are we now? Climacteric 2011; 14: 515-528.

17. Mintziori G, Lambrinoudaki I, Goulis DG, et al. EMAS position statement: Non-hormonal management of menopausal vasomotor symptoms. Maturitas 2015; 81: 410-413

18. Kravitz HM, Ganz PA, Bromberger J, et al. Sleep difficulty in women at midlife: a community survey of sleep and the menopausal transition. Menopause 2003; 10: 19-28.

19. Kravitz HM, Avery E, Sowers M, et al. Relationships between menopausal and mood symptoms and EEG sleep measures in a multi-ethnic sample of middle-aged women: the SWAN sleep study. Sleep 2011; 34 1221-1232.

20. Hall MH, Okun ML, Sowers M, et al. Sleep is associated with the metabolic syndrome in a multi-ethnic cohort of midlife women: the SWAN Sleep Study. Sleep 2012; 35: 783-790.

21. Donati Sarti C, Graziottin A, Mincigrucci M, et al. Correlates of sexual functioning in Italian menopausal women. Climacteric 2010; 13: 447-456.

22. Santoro N, Komi J. Prevalence and impact of vaginal symptoms among postmenopausal women. J Sex Med 2009; 6: 2133-2142.

23. Campbell KE, Dennerstein L, Finch S, Szoeke CE. Impact of menopausal status on negative mood and depressive symptoms in a longitudinal sample spanning 20 years. Menopause 2017; 24: 490-496.

24. Bromberger JT, Matthews KA, Schott LL, et al. Depressive symptoms during the menopausal transition: the Study of Women's Health Across the Nation (SWAN). J Affect Disord 2007; 103: 267-272.

25. Soares CN. Mood disorders in midlife women: understanding the critical window and its clinical implications. Menopause 2014; 21: 198-206.

26. Worsley R, Bell R, Kulkarni J, Davis SR. The association between vasomotor symptoms and depression during perimenopause: a systematic review. Maturitas 2014; 77: 111-117.

27. Natari RB, Clavarino AM, McGuire TM, et al. The bidirectional relationship between vasomotor symptoms and depression across the menopausal transition: a systematic review of longitudinal studies. Menopause 2018; 25: 109-120.

28. de Kruif M, Spijker AT, Molendijk ML. Depression during the perimenopause: A meta-analysis. J Affect Disord 2016; 206: 174-180.

29. Reed SD, Ludman EJ, Newton KM, et al. Depressive symptoms and menopausal burden in the midlife. Maturitas 2009; 62: 306-310.

30. Vivian-Taylor J, Hickey M. Menopause and depression: is there a link? Maturitas 2014; 79: 142-146.

31. Vousoura E, Spyropoulou AC, Koundi KL, et al. Vasomotor and depression symptoms may be associated with different sleep disturbance patterns in postmenopausal women. Menopause 2015; 22: 1053-1057.

32. Jones HJ, Zak R, Lee KA. Sleep Disturbances in Midlife Women at the Cusp of the Menopausal Transition. J Clin Sleep Med 2018; 14: 1127 1133.

33. Pinkerton JV, Abraham L, Bushmakin AG, et al. Relationship between changes in vasomotor symptoms and changes in menopause-specific quality of life and sleep parameters. Menopause 2016; 23: 1060-1066. 
34. Vincent AJ, Ranasinha S, Sayakhot P, et al. Sleep difficulty mediates effects of vasomotor symptoms on mood in younger breast cancer survivors. Climacteric 2014; 17: 598-604.

35. Kravitz HM, Zheng H, Bromberger JT, et al. An actigraphy study of sleep and pain in midlife women: the Study of Women's Health Across the Nation Sleep Study. Menopause 2015; 22: 710-718.

36. Ghorbani M, Azhari S, Esmaily HA, Ghanbari Hashemabadi BA. Investigation of the relationship between personality characteristics and vasomotor symptoms in menopausal women. Iran J Nurs Midwifery Res 2016; 21: 441-447.

37. Ormel J, Jeronimus BF, Kotov R, et al. Neuroticism and common menta disorders: meaning and utility of a complex relationship. Clin Psycho Rev 2013; 33: 686-697.

38. Bal MD, Sahin NH. The effects of personality traits on quality of life Menopause 2011; 18: 1309-1316.

39. Lin MF, Ko HC, Wu JY, Chang FM. The impact of extroversion or menopause status on depressive symptoms among climacteric women in Taiwan: neuroticism as moderator or mediator? Menopause 2008; 15: 138-143.

40. Chou CH, Ko HC, Wu JY, et al. Effect of previous diagnoses of depression, menopause status, vasomotor symptoms, and neuroticism on depressive symptoms among climacteric women: A 30-month follow-up. Taiwan J Obstet Gynecol 2015; 54: 385-389.

41. Constantine GD, Graham S, Clerinx C, et al. Behaviours and attitudes influencing treatment decisions for menopausal symptoms in five European countries. Post Reprod Health 2016; 22: 112-122. 